\title{
Reciprocity in international student exchange: Challenges posed by neo-colonialism and the dominance of the Western voice
}

\author{
Ines Zuchowski ${ }^{1}$, Narayan Gopalkrishnan ${ }^{1}$, Julie King ${ }^{2}$, Abraham Francis ${ }^{1}$
}

\begin{abstract}
INTRODUCTION: Internationalisation of social work education is part of a rapidly growing international tertiary education sector; one that is actively being promoted by governments and universities to support student learning and engagement and to develop global citizens. International partnership programmes form a core part of the internationalisation of social work education, and these programmes may involve inequity in the benefits to the different partners. This article critically reflects on, and explores, concepts of reciprocity and collaboration in international social work student exchanges with a specific focus on exchanges between Australia and the Asia-Pacific.

METHODS: A critical lens was applied to the literature that conceptualises international student exchanges with a particular focus on reciprocity and collaboration. The concept of neo-colonialism is used to explore international student exchanges and consider ways forward; the term is used to refer to newer and more subtle forms of colonialism that are often based on linguistic or cultural domination. The discussion is further drawn out with anecdotal evidence from the authors' own long-term engagement with international student exchange as well as an Australian government funded project "Going Places" that explores internationalisation in social work education.
\end{abstract}

FINDINGS: A critical review of the literature highlights the continued dominance of the Western voice and issues of neo-colonialism as challenges to ensuring equitable processes in the internationalisation of social work education. Reciprocity is a contested concept that needs deep engagement to support transformative partnerships.

CONCLUSIONS: It is argued that concepts of reciprocity, voice and collaboration have to be carefully considered in order to create transformative partnerships in international social work education.

KEYWORDS: international student exchange, international social work, social work education, reciprocity, partnership, neo-colonialism

The internationalisation of the tertiary education sector has grown considerably in the past decade. In Australia, internationalisation has been actively promoted by both government and universities to support student learning and engagement in order to develop global citizens. This is reflected in the growing body of literature addressing this area (Caruana \& Spurling, 2007; Jones \& Brown, 2007; Schattle, 2008; Stearns, 2009). The drive towards the internationalisation of education is recognised by Bourne (2011), "the challenges for higher education today are the need to recognise the global reality within which learning takes place. This
1 James Cook University, Australia

${ }^{2}$ Queensland University of Technology, Australia
AOTEAROA NEW ZEALAND SOCIAL WORK 29(1), 77-87.

CORRESPONDENCE TO: Ines Zuchowski ines.zuchowski@jcu.edu.au 
means seeing globalisation not only as economic, but also as social, cultural and environmental"' (p. 559).

This article emerges from an Australian Government Office of Learning and Teaching (OLT) funded research project, "Going Places," that is exploring internationalisation in social work education. This project is undertaken jointly by two Australian universities, one university in Thailand and one in India. The project aims to document and analyse current practice, and to facilitate the development of guidelines, strategies and resources that improve practice in the area of international student exchange for the discipline of social work. International exchange in this project includes short-term international student exchanges, often small groups of students accompanied by university staff and locally supported by a host organisation, as well as international field placements meeting the placement requirement of the accrediting professional social work organisation. Shortterm exchange programmes range generally from a week up to a month, while field education placements are designed to meet the professional requirements of 500 hours (Australian Association of Social Workers (AASW), 2012), i.e., three-four months of placement. While the terminology of student exchange is used, this does not necessary mean an exchange in the real sense of the word, and the movements of people are often unidirectional, especially from the Global North to the Global South.

This article draws on the literature review from this project and anecdotal data from the authors' experiences in this area to critically reflect on, and explore, concepts of reciprocity and collaboration in international social work student exchanges, with specific focus on exchanges between Australia and the Indo-Pacific region. An overview of internationalisation of social work education is provided and the context of these exchanges is critically reviewed in relation to colonisation and the dominance of the Western voice. This informs a discussion of the concept of reciprocity and of suggestions for future developments in order to create transformative partnerships in international social work education.

\section{Background}

In social work education and in the social work profession, internationalisation has been equated with international social work, a concept that is broadly debated in the social work literature (Healy, 2001; Hugman, Moosa-Mitha, \& Moyo, 2010; Hokenstad, Khinduka, \& Midgley, 1992; Lyons, Manion, \& Carlsen, 2006; Payne \& Askeland, 2008). The term remains contested, with different positions taken on what it signifies (Dominelli \& Hackett, 2012). International social work can be viewed as international professional practice and the capacity for international action to be taken by the profession (Healy, 2001). International action in this context has four dimensions:

(1) internationally related domestic practice and advocacy; (2) professional exchange; (3) international practice; and (4) international policy development and advocacy (Healy, 2001). Grace et al. (2013, p. 121) argue that "[i]nternationalisation of social work education is driven by student diversity as well as by employer demand, the profession internationally, and by universities." However, internationalisation is a reality and educational institutions have to respond to this in a way that supports student engagement and learning. In this context, internationalisation incorporates a series of international activities including academic mobility for students and teachers; in linkages, partnerships, and projects; and international academic programmes and research initiatives (Knight, 2004).

Among the processes of internationalisation, social work education values international student placements and exchanges as a way for students to develop skills and attitudes to function effectively in a global world. These placements can enhance students' ability to work across cultures and with those who have different cultural assumptions. As such 
they have important implications for social work education (Engstrom \& Jones, 2007). Moreover, they provide an opportunity for students to comprehend the complexity of the globalised world, at all levels. Issues that have been explored in a theoretical context in the classroom can be brought to light in international exchanges where students come to understand the context and interrelatedness of issues such poverty and wealth, political and cultural differences and the impact of climate change.

Australian universities are encouraging students to experience international placements and study abroad as part of the Australian government's wider commitment to internationalising education (Universities Australia (UA), 2013). Funding initiatives, as for example the "New Colombo Plan," deliver mobility grants that enable students to gain international experiences in the Indo-Pacific region (Department of Foreign Affairs and Trade (DFAT), 2014). The aim is to create a two-way flow of students, and the deepening of relationships that can lead to a transformation of the Indo-Pacific region (DFAT, 2014). Social work students need to be prepared to consider the impact of the global on their local work in an increasingly globalised world (Cleak \& Fox, 2011). International exchanges can play a part in preparing social work students for the complexities of intercultural local and global practice contexts (Nuttman-Schwartz \& Berger, 2012). Anecdotally, there has been a marked increase in students from Australian universities travelling to countries in South Asia and South-East Asia for international field placements. However, the differing contexts of the partner institutions within these placement programmes raise a number of issues around reciprocity, power and benefit. Student exchanges between schools of social work in countries with differing levels of economic development and colonial histories raise the potential for professional imperialism (Ashcroft, Griffiths, \& Tiffin, 1995). There is a risk that the benefits of these activities are "... one-directional and flow to the more powerful" (Cemlyn, 1995 cited in Engstrom \& Jones, 2007, p. 149). These student programmes have been referred to as "one-way traffic," and "social work tourism" and, as Mukherjee (2011, p. 8) suggests, may lead to the intake of students who only want to "participate as a tourist without seeking any academic credit." The literature does not provide any answers to these issues. However, it suggests that there is an increased demand for student exchange programmes and increased interest among universities to engage in these activities.

Over the last couple of years, the authors of this article have been involved in facilitating international student exchanges between Australian universities and universities in the Global South, including India, Thailand, and Vietnam as well as with international non-government organisations in Cambodia. While these activities provided excellent opportunities for students on exchange to understand cross-cultural differences and the social realities around them, they raised some fundamental questions around the ongoing impacts of neo-colonialism, the nature of equity, reciprocity and relevance for the host institutions. In this article, the authors apply a critical lens in order to explore the cultural and socio-political dimensions of these terms based on the literature, critical reflection, and professional experience. The concepts of colonialism and neo-colonialism in the delivery of education are discussed and used to explore current delivery of international student exchanges and draw implications for social work education.

\section{Neo-colonialism and international student exchanges}

Razack (2005, p. 87) argues that we

"appear to be plunging headlong into more international commitments and not stopping to fully analyse the effects." International student exchanges are one kind of international commitment that lends itself to this critique. A number of international student exchange programmes occur between institutions and countries of the 
Global North and Global South (terms that are geographically inaccurate in many cases but slightly less pejorative than the alternatives). The nature of the power dimensions that exist between these countries is central to relationships that can be built across them and yet not much is done in terms of examining the nature of these differentials and their impact on collaboration. Tasse (2006) suggests it is common knowledge that, traditionally, relationships between the Global North and Global South have been based on domination rather than cooperation, and that many of these relationships persist on this basis. To discuss the nature of these relationships, Haug (2005) uses the metaphor of "couple therapy" to posit that, in a relationship where one partner has dominated the other for long periods of time, it would be inappropriate to move on without addressing, and compensating for, this power differential. This metaphor works well in considering the nature of a number of the relationships that are emerging in the context of international student exchange.

The terms colonisation or colonialism have been used to examine the ways in which countries, largely of the Global North, extended their power over many countries of the Global South through exploitation of people and resources (Razack, 2002). Colonisation, which was largely extended through military or political means, was mostly terminated by the end of the 20th century, and has been followed by an era dominated by newer forms of colonisation, referred to as neo-colonialism, that are far more subtle and based on the imposition of language and culture rather than through brute force. Askeland and Payne (2006) expore these aspects of neo-colonialism, pointing to the ways in which cultural and social relations can impose and maintain power and hegemony. Western knowledge systems, media control and English as the dominant global language, all contribute to creating an environment that sustains hegemony (Askeland \& Payne, 2006; Razack, 2009).
Neo-colonialism is of concern in education in general and in social work education in particular. "Education is perhaps the most insidious and in some ways the most cryptic of colonial survivals, older systems now passing, sometimes imperceptibly, into neo-colonialist configurations" (Ashcroft et al., 1995, p. 425). Lecture rooms and their extensions in the form of student placements, are sites that can easily form part of the hegemonic neo-colonial discourse unless deep analysis and contestation enable alternate voices to be heard. Students and academics from the Global North and Global South can reinforce the dominant positioning of Western ideas and knowledge systems, even though these may often be quite inappropriate and/or inadequate in different contexts (Haug, 2005). This can especially be an issue where the discussion remains within an "apolitical" agenda, and does not include the historical context of colonisation, imperialism and hegemony (Joseph, 2008; Razack, 2009).

The production and flow of knowledge in social work continues to be dominated by Western thought and knowledge systems. Kreitzer and Wilson (2010) argue that the universal standards adopted by the International Federation of Social Workers (IFSW) and the International Association of Schools of Social Work are heavily influenced by Western social work discourses. The authors maintain that this is evidence that Western social work education continues to be the dominant paradigm in international social work education and practice. Social work education is positioned within the global neo-colonial space in that those who have the resources to produce and disseminate their knowledge systems effectively are able to occupy the centre while all the others remain on the margins (Askeland \& Payne, 2006).

Haug's (2005) research draws out elements of the dominant discourse in international social work, all of which are equally applicable to international student exchange. She states that all international social work 
material she has read seemed "blind not only to their perpetuation of a paternalistic framing of non-Western cultures, knowledge systems and social care traditions, but also to the elitism and exclusion within this ostensibly global conversation" (Haug, 2005, p. 127). Haug highlights that the emerging discourse of social work as a superior local tradition devalues other social care systems and argues that, in countries of the Global South, there are long traditions of social care based on strengths of family, clan, or community, traditions that continue to provide many of the social supports that social work seeks to provide in the Global North (Haug, 2005). If the dominant discourse belittles and sidelines these systems towards the development of a professional social work paradigm, it can exacerbate social issues already present in society or create new ones without any attendant benefits. In the context of international social work placements this can lead to "professional imperialism" based on a lack of reciprocity and inadequate analysis of the nature of these relationships (Razack, 2005).

On the other hand, Noble argues that internationalisation of social work can be a vehicle towards fracturing of Anglo-Western pedagogical hegemony and contributing to multicultural awareness in social work curricula (Noble, 2004). She considers internationalisation of social work education in the context of developing international guidelines, and cautions that, while this can be an opportunity to hear and include multiple voices, there needs to be focus towards minimisation of the Western voice and the challenging of academic authority over knowledge (Noble, 2004). There is a growing awareness of the needs for countries in the Global South to develop indigenous literature in social work education-Raju (2014), for example, calls for a social work curriculum that addresses the issues and problems in the Indian context. However, at this point in time, there is still an emphasis of the Western voice in the Global South through the implementation of Western pedagogies, utilisation of Western literature and texts in educational institutions and the predominance of Western models of social work practice (Raju, 2014).

\section{Collaboration and partnerships in international student exchanges}

The nature of collaboration and partnership in international student exchanges emerges as a vexed issue in the literature. At the simplest level, collaboration and or partnership should involve the movements of people and knowledge both ways, from the Global South to the Global North and vice versa. However, several authors point to the fact that the flows remain largely unidirectional with both knowledge and people flowing from the Global North to the Global South (Hugman, Moose-Mitha, \& Moyo, 2010; Joseph, 2008). Particularly in the context of the movements of people in the social work field, Hugman et al. describe the current situation as one where it is "the social workers of the materially rich nation-states who are able to travel the world without restriction, while most people from the global South are under heavy surveillance, their travel restricted and information technology limited" (2010, p. 636).

Further, collaboration at times can be difficult to put into practice, as for example when administrative aspects of international exchange become an extra task for academic staff in universities both in the North and the South. Bell (2008) discusses the difficulty of ensuring collaborative processes, discussion and reflection for academic staff involved in facilitating an international study experience for Singaporean students in Australia, especially in the light of time and resource constraints, as well as the top-down nature of programme development. Many universities also report that their outward mobility programmes are under-resourced (Aim Overseas, 2013).

Another constraint in implementing collaborative initiatives is found in the economic discrepancies that make it 
difficult for international partners from the Global South to utilise international exchange opportunities (Miles et al., 2016). Additionally, economic inequities between the Global North and South present a key barrier to the progress of reciprocity (Miles et al., 2016).

Very few voices from the host organisations in the Global South are represented in the literature. Even where they are, the main focus remains student experience, for example, the benefit of hosting a placement being seen as engaging deeper with their own policies and procedures in order to present them appropriately to the incoming student (Nickson, Kuruleca, \& Clarke, 2009). International student placements can offer new ideas and assist in development of projects, as in the example of a drama project to respond to child trafficking (Nickson, Briscoe, Maconachie, \& Browskowski, 2011). The organisation, however, identified that supporting the student as a social work student rather than a volunteer was challenging, and raised the need for professional support and supervision that was provided by an external supervisor remunerated by the Australian university (Nickson et al., 2011).

Heron (2006) argues that social work must critically analyse the impacts on host organisations and communities. Of concern are the cumulative impacts of student field placements and their contribution to the increasing number of Western, middleclass people seeking short-term (less than one year) international experiences in the Global South. The constant turnover, particularly in high-demand NGOs, may be destabilising, drain their meagre human resources, and have impacts on their longterm sustainability (Heron, 2006). There are also power imbalances when institutions from the Global North attempt to enter into partnerships with NGOs in the Global South as, due to their dependence on foreign funding, there can be an unspoken perception that their cooperation is required to comply with, or attract, funding aid (Heron, 2006).
Overall, even if these concerns are addressed, there is still no consensus as to how to avoid the trap of preventing the Western voice from dominating, even if a postmodern critique and decolonised curricula are encouraged to form a basis of core curricula. As Noble describes it:

Even the commitment to "letting others speak" and engaging in "inclusive dialogue" can be viewed as another form of colonialism, as the underlying control in the dissemination and construction of knowledge or the process of "letting go" of privilege and power can still be seen as a process dominated by Western ideology. It is difficult to hear and respect other knowledges when they are still marginalised and coming from a subordinated subject position. (2004, p. 535)

The concept of reciprocity can be viewed as a way forward in developing more equitable relationships (Kreitzer \& Wilson, 2010). It is possible that reciprocal arrangements between institutions in the North and South would enable many of the problems discussed in this section to be managed more effectively. However, the nature of reciprocity and the reciprocal arrangements that exist today need to be examined more closely to in order to bring out the vexed nature of the issues involved.

\section{Reciprocity}

Reciprocity is an important concept in community engagement and in international exchange programmes, yet it is often used in practice without adequate, in-depth conceptualisation and critical examination to arrive at a shared understanding of the concept. As has been observed from the field experiences of the authors, understandings and applications reciprocity vary widely and, when operationalised without clear articulation and proper purpose, the differing conceptualisations of reciprocity can lead to confusion in practice and can hinder the effectiveness of programmes (Graeber, 2001). While at the simplest level, 
reciprocity can be viewed as exchange between people for mutual benefit, the context within which this happens is critical to the currency of this exchange (Jenkins, 2015). The reciprocity arrangements that exist within families and friends can be quite distinct from those that exist in more professional interactions, including those implicit in international social work.

Sahlins' (1972, cited in Thomas \& Worrall, 2002) typology of reciprocity provides some direction in examining the forms of reciprocity that exist in international social work education. Sahlins discusses "generalized reciprocity" as transactions that focus on the social aspect and where the precise balance in the exchange is not emphasised as in gift giving. "Balanced reciprocity," on the other hand, involves more precise and time-bound exchanges, very much in sync with modern market systems, and "negative reciprocity" involves parties trying to maximise their gains without loss to themselves, as in forms of theft.

Given the paucity of literature from the Global South, the notion of reciprocity draws heavily on literature from the Global North. This raises the issue of its validity relative to exploring relationships between the North and the South and the possibility that it is just one more element in the neo-colonial project. There is clearly a need for research that explores this concept at a deeper level from the point of view of the Global Souththe "Going Places" project that the authors are currently engaged with will enable some of these hidden voices to emerge. For example, one of the partnerships that the authors have been involved in is between organisations in Australia and India.

Culturally, reciprocity can be conceptualised as a form of gratitude in the Indian context, as an attitude of acknowledgment, appreciation and a sense of cooperation that culminates in a spirit of respect for all involved. This has been a similar experience for the authors' partnerships in Cambodia. This is in keeping with Sahlins' notion of generalized reciprocity. A commonly used
Sanskrit term in India, Athithi devo bhava [A guest is akin to God], implies that a guest must be treated with the level of hospitality one would offer to God. The Bhagwat Gita, a central sacred text in the Hindu religion, emphasises work without the expectation of reward as:

\section{Karmanye Vaadhika-raste, Maa Phaleshu Kadachana; \\ Maa karma-phala-hetur-bhoorma, MaTe sangostwakarmini. \\ (Bhagavad Gita, Chapter 2; Verse 47)}

[You have the right to work only but never to its fruits. Let not the fruits of action be your motive. Nor let your attachment be to inaction.]

(http:/ / gitaglobal.com/bhagavad-gitachapter-2-sloka-47-part-1/)

This verse, popular in many parts of India, raises important issues during discussions with Indian partners on aspects of reciprocity. From Northern perspectives, there is often an emphasis on quid pro quo, where the benefits our students have enjoyed on placement with the Indian partners should be reciprocated equally with benefits provided to Indian students. From an Indian perspective, that may not necessarily be the case, as the visiting students and academics are being treated as honoured visitors without attendant expectation of an equal return. This raises the possibilities of differences between the models of reciprocity across the partner organisations from the Global North and Global South, where one may be based on the notion of balanced reciprocity and the other on a more generalised form of reciprocity.

Jamesson, Clayton, and Jaeger (2011) make a distinction between thin and thick reciprocity.

Transactional partnerships are grounded in a minimalist or 'thin' understanding of the commitment to reciprocity that has become the standard for authentic engagement; they enact the mutually- 
beneficial exchange of resources but do not go beyond that to mutual transformation" (Jameson et al., 2011, p. 263);

'Thick' understanding of reciprocity, one that emphasizes shared voice and power and insists upon collaborative knowledge construction and joint ownership of work processes and products-aligns well with more democratic approaches to civic engagement and encourages all partners to grow and to challenge and support one another's growth" (2011, p. 264).

From a social work perspective, the notion of thick reciprocity fits well into the values and ethics embedded in the profession.

Thin reciprocity is more aligned to market exchange and mutual benefit, while the ideas of collaborative knowledge construction, and joint ownership move beyond to goals of transformation and empowerment. Enos and Morton (2003) differentiate between transactional partnerships and transformational partnerships as follows: transactional partnerships, are those that aim for a mutually beneficial exchange of goods and/ or services, are task-oriented, work within established systems, and do not produce deep change; transformational partnerships are those that involve deeper commitments and expectations of shifts in identities and values, challenge norms and systems, and have outcomes that extend beyond mutual benefit (reciprocity) to mutual growth and change. Here, the concept of reciprocity has been classified as transactional rather than transformative. In some cases, the partnerships become less than mutually beneficial and, in some instances, may be harmful to, or even exploitative of, one or more of the participants for a number of reasons. Hence, it is relevant to review the distinction between exploitative, transactional, and transformational relationships. The question is, what is the relationship that is unfolding during this process of partnerships? Cranton (2006) describes these as "authentic relationships" that "choose to act so as to foster the growth and development of each other's being" (p. 7).

\section{Towards alternative ways forward}

From a social work perspective, as well as from an intercultural perspective, drawing on the different cultures involved in NorthSouth partnerships, there is a clear need to go beyond the transactional and towards the developing of transformative partnerships based on thick understandings of reciprocity. Experiences in a range of international collaboration activities suggest that dialogue and relationships are essential to avoiding further oppression of the host countries (Brydon et al., 2014). There is clearly a need to avoid processes that strengthen professional imperialism and paternalistic framing of the Other. We need to understand more about what processes work well in international collaboration and what can provide genuinely transformational relationships with partner organisations, relationships that may assist both sides in sustaining practical needs such as field placements and student exchanges and contribute towards the sustainability of the organisations and communities. This is particularly important to the social work profession, whose responsibility internationally is delineated in the IFSW's definition of the core role of social work as well as within the IFSW human rights policy (IFSW, 2004). The standards state that social work programmes are required to ensure that students apply "social work values, ethical principles, knowledge and skills to confront inequality, and social, political and economic injustices" (IFSW, 2004, Standard 4.2.3). Thus, congruency between how the institution and school conduct themselves and these learning outcomes is essential. Further, the AASW Code of Ethics states that the core values of social work are respect for persons, social justice and professional integrity (AASW, 2010). Sections 5.1.3 j, 5.1.4 $\mathrm{e}$, and 5.4.1 c (respectively) specifically require social workers to act in a socially just manner, with integrity, and challenge practices that are in any way oppressive or culturally inappropriate (AASW, 2010). All of this emphasises the need for international social work to take place in congruence with these ethical standards. 
For the social work profession, it would be essential to ensure that the internationalisation of social work education is congruent with the ethical standards and mission of the profession. Two key strategies towards safeguarding this are to ensure an ethical framework for international work exists and to work towards developing thick reciprocity. Internationalisation of social work education needs to be based on a sound framework for ethical practice, congruent with the international mission statement for social work and anticolonising practices. This would involve an exploration of how to minimise Western voices and positioning in the international student exchange programme and a critical exploration of the lenses with which we view, plan, implement and evaluate student exchanges. Development of thick reciprocity can result from such an exploration, when the starting point is a practice framework steeped in the values and mission of the profession, and supported by critical reflection that considers voice, collaboration, and the goals and intention of the exchange. Examples to move towards thick reciprocity can be found in the literature.

To aid in achieving reciprocity, Lough (2009), in the context of field placement, suggests that host organisations must have a role in determining the field placement outcomes ensuring the student fulfils a role that is of genuine assistance to the host. A similar principle has to be part of any form of international social work exchange, in that organisations from the Global South need to be part of the decision-making process. For genuine knowledge exchange to occur, both parties must be adequately prepared: students and staff from the Global North and Global South must possess a genuine openness and awareness of their cultural biases and value their own knowledge and assets (Mirsky \& Barasch, 2004). Cultural mediators, professionals or nonprofessionals with expertise in both cultures are suggested by Mirsky and Barasch (2004) as helpful in this process. Experiences in a range of international collaboration activities suggest that dialogue, relationships and power sharing are essential to avoiding further oppression of the host countries and in engaging in genuine collaboration (Brydon et al., 2014; Tesoriero \& Vicary, 2007). An example of explicitly addressing reciprocity is provided by Tesoriero and Vicary's account of a partnership between an Australian University and an Indian organisation. In this situation there was clarity from the beginning of the project as to what meaningful reciprocity would entail. Whilst exchange was part of this understanding, other measures to ensure reciprocity included students completing tasks that would not normally be able to be achieved by the partner and would be of benefit to their communities, and publication of the organisation's work (Tesoriero \& Vicary, 2007). Following due process will, to some extent, address the key structural issues delineated earlier, such as the impact in the Global South of a lack of mobility and time, lack of power over resources, and lack of power in terms of the generation and dissemination of knowledge. However, more critical thinking and research is also clearly needed to go beyond current understandings of what processes work well in international collaboration and what can provide genuinely reciprocal relationships among partner organisations. The goal of genuine transformational partnerships is one that needs to be central to the work of international social work.

\section{Conclusions}

A critical review of the literature and anecdotal experiences about international student exchanges has shown that current practice is in danger of being neo-colonist practice. Concepts of reciprocity, voice and collaboration have to be carefully considered in order to create transformative partnerships in international social work education. Reciprocity itself has to be understood as more than quid pro quo, but as a process of engagement that finds a shared voice and power, facilitates meaningful collaboration and joint 
construction and ownership of processes and outcomes (Jamesson et al., 2011). International social work education is only congruent with the professions' ethical standards and mission when there are genuine transformational partnerships and reciprocity.

\section{References}

Australian Association of Social Workers (AASW). (2010). Code of ethics. Canberra, ACT: Author.

AASW. (2012). Australian social work education and accreditation standards ASWEAS 2012 v1.2(1) (pp. 1-27). Canberra, ACT: Author

Aim Overseas. (2011). Outbound Mobility Best Practice Guide for Australian Universities. Accessed 12.12.2016 from http://www.studyoverseas.gov.au/sites/studyoverseas/ resources/Documents/ombpgau/OMBPG.pdf

Ashcroft, B., Griffiths, G., \& Tiffin, H. (1995). Introduction In B. Ashcroft, G. Griffiths, \& H. Tiffin (Eds.), The postcolonial studies reader (pp. 425-427). London, UK: Routledge.

Askeland, G. A., \& Payne, M. (2006). Social work education's cultural hegemony. International Social Work, 49(6), 731-743.

Bell, M. (2008). Beyond the supermarket: Lost opportunities in summer study abroad for Singapore sojourners in Australia. International Journal of Asia Pacific Studies, 4(1), 61-78.

Bourne, D. (2011). From internationalization to global perspectives. Higher Education Research and Development, 30(5), 559-571. doi:10.1080/07294360. 2011.598447

Brydon, K., Kamasua, J., Flynn, C., Mason, R., Au, R., Ayius, D., \& Hampson, R. (2014). Developing an international social work education collaboration: A partnership approach between Monash University, Australia and University of Papua New Guinea. International Social Work, 57(6), 590-604. doi:10.1177/0020872812444939

Caruana, V., \& Spurling, N. (2007). The internationalisation of UK higher education: A review of selected material. Retrieved from http://www.heacademy.ac.uk/resources/ detail/the_internationalisation_of_uk_he

Cleak, H., \& Fox, M. (2011). Current Australian programs for international field placements. In C. Noble \& M. Henrickson (Eds.), Social work field education and supervision across Asia Pacific (pp. 23-44). Sydney, NSW: Sydney University Press.

Cranton, P. (2006). Fostering authentic relationships in the transformative classroom. New Directions for Adult and Continuing Education, 109, 5-13.

Department of Foreign Affairs and Trade (DFAT). (2014). The new Colombo Plan. Canberra, ACT: Author. Retrieved from http://www.dfat.gov.au/new-colombo-plan/about.html

Dominelli, L., \& Hackett, S. (2012). Internationalising social work theory and practice. International Social Work, 55, 151-153. doi:10.1177/0020872811435075

Engstrom, D., \& Jones, L. P. (2007). A broadened horizon: The value of international social work internships. Social Work Education: The International Journal, 26(2), 136-150.
Enos, S., \& Morton, K. (2003). Developing a theory and practice of campus community partnerships. In B. Jacoby \& Associates (Eds.), Building partnerships for servicelearning (pp. 20-24). San Francisco, CA: Jossey-Bass.

Grace, M., Townsend, R., Testa, D., Fox, J., O'Maley, P., Custance, J., \& Daddow, A. (2013). Student diversity as grass roots internationalisation in social work education. Advances in Social Work \& Welfare Education, 15(1), 121-135.

Graeber, D. (2001). Toward an anthropological theory of value: The false coin of our own dreams. New York, NY: Palgrave.

Hanlen, P. (2011). Community engagement: Managers' viewpoints. In C. Noble \& M. Hendrickson (Eds.), Social work field education and supervision across Asia Pacific (pp. 221-242). Sydney, NSW: Sydney University Press.

Haug, E. (2005). Critical reflections on the emerging discourse of international social work. International Social Work, 48(2), 126-135.

Healy, L. M. (2001). International social work: Professional action in an interdependent world. New York, NY: Oxford University Press.

Heron, B. (2006). Critically considering international social work practica. Critical Social Work, 7(2). http://www1.uwindsor.ca/criticalsocialwork/criticallyconsidering-international-social-work-practica

Hokenstad, M. C., Khinduka, S. K., \& Midgley, J. (1992). The world of international social work. In M. C. Hokenstad, S. K. Khinduka, \& J. Midgley (Eds.), Profiles in international social work (pp. 1-11). Washington, DC: NASW Press.

Hugman, R., Moosa-Mitha, M., \& Moyo, O. (2010). Towards a borderless social work: Reconsidering notions of international social work. International Social Work, 53(5), 629-643.

International Federation of Social Workers (IFSW). (2004). Global standards. Retrieved from http://ifsw.org/policies/ global-standards/

Jamesson, J. K., Clayton, P. H., \& Jaeger, A. J. (2011). Community-engaged scholarship through mutually transformative partnerships. In L. Harter, J. HamelLambert, \& J. Millesen (Eds.), Participatory partnerships for social action and research (pp. 259-277). Dubuque, IA: Kendall Hunt.

Jenkins, D. (2015). Denying reciprocity. European Journal of Political Theory, 15(3), 1-21. doi:10.1177/1474885115569513

Jones, E., \& Brown, S. (Eds.). (2007). Internationalising higher education. London, UK: Routledge.

Joseph, C. (2008). Difference, subjectivities and power: (De)colonizing practices in internationalizing the curriculum. Intercultural Education, 19(1), 29-39. doi:10.1080/14675980701852350

Knight, J. (2004). Internationalization remodeled: Definition, approaches, and rationales. Journal of Studies in International Education, 8(1), 5-31.

Kreitzer, L., \& Wilson, M. (2010). Shifting perspectives on international alliances in social work: Lessons from Ghana and Nicaragua. International Social Work, 53(5), 701-719.

Lough, B. J. (2009). Principles of effective practice in international social work field placements. Journal of Social Work Education, 45(3), 467-480. doi:10.5175/ JSWE.2009.200800083 
Lyons, K., Manion, K., \& Carlsen, M. (2006). International perspectives on social work: global conditions and local practice. Houndmills, Basingstoke: Palgrave Macmillan.

Miles, D., Jones, P., Gopalkrishnan, N., Francis, A., Harris, N., Howard, E., ... Puthantharayil, G. (2016, July). Contested concepts of "partnership" in international student exchange programs. Proceedings of the $37^{\text {th }}$ HERDSA Annual International Conference; HERSDA 2016: 39th Higher Education Research and Development Society of Australasia Annual International Conference: The shape of higher education, Freemantle, WA, Australia.

Mirsky, J., \& Barasch, M. (2004). Facilitating a reciprocal international exchange in social work. Professional Development: The International Journal of Continuing Social Work Education, 7(3), 20-29.

Mukherjee, D (2011) Principles of effective transnational networking for global social work education: A case study, Journal of Global Social Work Practice, 4(1), pp.1-11.

Nickson, A., Briscoe, C., Maconachie, S., \& Browskowski, M. (2011). A Vietnamese and Australian cross-cultural field placement using community arts to heal and prevent child trafficking. In C. Noble \& M. Henrickson (Eds.), Social work field education and supervision across Asia Pacific (pp. 145-167). Sydney, NSW: Sydney University Press.

Nickson, A., Kuruleca, S., \& Clarke, M. (2009). Fijian and Australian social work learning through field education. In C. Noble, M. Henrickson, \& I. Y. Han (Eds.), Social work education: Voices from the Asia Pacific (pp. 50-71). Carton North, VIC: The Vulgar Press.

Noble, C. (2004). Social work education, training and standards in the Asia-Pacific region. Social Work Education, 23(5), 527-536. doi:10.1080/0261547042000252262

Nuttman-Schwartz, O., \& Berger, R. (2012). Field education in international social work: Where are we and where should we go. International Social Work, 55, 225-243. doi:10.1177/0020872811414597

Payne, M. \& Askeland, G. A. (2008). Globalization and international social work: Postmodern change and challenge. Burlington, VT: Ashgate Publishing.

Raju, K. (2014). Resilient social work -The gracious way. New Delhi, India: Ane Books.

Razack, N. (2002). A critical examination of international student exchanges. International Social Work, 45(2), 251-265.

Razack, N. (2005). "Bodies on the move": Spatialized locations, identities, and nationality in international work. Social Justice, 32(4), 87-104.

Razack, N. (2009). Decolonizing the pedagogy and practice of international social work. International Social Work, 52(1), 9-21. doi:10.1177/0020872808097748

Sahlins, M. (1972). Stone age economics. Chicago, IL: Aldine-Atherton.

Schattle, H. (2008). The practices of global citizenship. Lanham, MD: Rowman \& Littlefield.

Stearns, P. (2009). Educating global citizens in colleges and universities. New York, NY: Routledge.

Tasse, A. (2006). News and views . . from IASSW. International Social Work, 49(1), 137-139.

Tesoriero, F., \& Vicary, A. (2007, October) Achieving an ethical Australian-Indian relationship through a reciprocal student mobility program in social work., 1-9. Paper presented at the Australian International Education Conference. Retrieved from http://aiec.idp.com/uploads/ pdf/paper_Tesoriero\&Vicary.pdf

Thomas, J. P., \& Worrall, T. (2002). Gift-giving, quasi-credit and reciprocity. Rationality and Society, 14(3), 308-352. doi:10.1177/1043463102014003003

Universities Australia. (2013). An agenda for Australian Higher Education 2013-2016. Retrieved from https://www.universitiesaustralia.edu.au/ 